\title{
Rapid Loss of Dendritic HCN Channel Expression in Hippocampal Pyramidal Neurons following Status Epilepticus
}

\author{
Sangwook Jung, ${ }^{1}$ Lindsay N. Warner, ${ }^{2}$ Julika Pitsch, ${ }^{3}$ Albert J. Becker, ${ }^{3}$ and Nicholas P. Poolos ${ }^{1}$ \\ ${ }^{1}$ Department of Neurology and Regional Epilepsy Center and ${ }^{2}$ Neurobiology Program, University of Washington, Seattle, Washington 98104, and \\ ${ }^{3}$ Department of Neuropathology, University of Bonn Medical Center, 53105 Bonn, Germany
}

\begin{abstract}
Epilepsy is associated with loss of expression and function of hyperpolarization-activated, cyclic nucleotide-gated (HCN) ion channels. Previously, we showed that loss of HCN channel-mediated current $\left(I_{\mathrm{h}}\right)$ occurred in the dendrites of CA1 hippocampal pyramidal neurons after pilocarpine-induced status epilepticus (SE), accompanied by loss of $\mathrm{HCN} 1$ channel protein expression. However, the precise onset and mechanistic basis of HCN1 channel loss post-SE was unclear, particularly whether it preceded the onset of spontaneous recurrent seizures and could contribute to epileptogenesis or development of the epileptic state. Here, we found that loss of $I_{\mathrm{h}}$ and $\mathrm{HCN} 1$ channel expression began within an hour after SE and involved sequential processes of dendritic $\mathrm{HCN} 1$ channel internalization, delayed loss of protein expression, and later downregulation of mRNA expression. We also found that an in vitro SE model reproduced the rapid loss of dendritic $I_{\mathrm{h}}$, demonstrating that this phenomenon was not specific to in vivo SE. Together, these results show that HCN1 channelopathy begins rapidly and persists after SE, involves both transcriptional and nontranscriptional mechanisms, and may be an early contributor to epileptogenesis.
\end{abstract}

\section{Introduction}

Hyperpolarization-activated, cyclic nucleotide-gated (HCN) channels are voltage-gated ion channels highly expressed in brain regions associated with seizure onset: cortex and hippocampus (principally the HCN1 subtype) and thalamus (primarily the HCN2 subtype). An abundance of evidence has established that HCN1 channels act to diminish the intrinsic excitability of pyramidal neurons in cortex and hippocampus (for review, see Lewis and Chetkovich, 2011). In these neurons, HCN channels are localized primarily to the apical dendrites where the majority of excitatory synaptic input occurs, and $I_{\mathrm{h}}$ is one of the few ionic conductances continuously active at resting potential, thus exerting an inhibitory influence on synaptic inputs by diminishing dendritic input resistance.

Loss of expression and function of HCN1 channels occurs in epilepsy. Entorhinal cortical neurons had loss of $I_{\mathrm{h}}$ and HCN1 channel protein expression following kainate (KA)-induced status epilepticus (SE) (Shah et al., 2004), and we found that loss of HCN1 channel function in CA1 hippocampal pyramidal neurons after pilocarpine-induced SE depended on two mechanisms: loss of dendritic $I_{\mathrm{h}}$ amplitude and HCN1 channel expression, and a hyperpolarizing shift in $I_{\mathrm{h}}$ voltage-dependent activation. While the gating

Received March 4, 2011; revised Aug. 16, 2011; accepted Aug. 17, 2011.

Author contributions: S.J. and N.P.P. designed research; S.J., L.N.W., J.P.P., and N.P.P. performed research; S.J., L.N.W., J.P., A.J.B., and N.P.P. analyzed data; S.J. and N.P.P. wrote the paper.

This work was supported by grants from the National Institutes of Health to N.P.P. (NS050229) and the Deutsche Forschungsgesellschaft (KFO, SFB TR3), Bundesministerium für Bildung und Forschung (NGFNplus), German-Israeli Research Fund, and Eurocores (EuroEpinomics) to A.J.B.

Correspondence should be addressed to Nicholas P. Poolos, University of Washington, Department of Neurology and Regional Epilepsy Center, Box 359745, 325 Ninth Avenue, Seattle, WA 98104. E-mail: npoolos@ u.washington.edu.

DOI:10.1523/JNEUROSCI.1148-11.2011

Copyright $\odot 2011$ the authors $\quad 0270-6474 / 11 / 3114291-05 \$ 15.00 / 0$ change was dependent on spontaneous seizures and mediated by downregulated phosphorylation signaling, the loss of expression was independent of seizures (Jung et al., 2007, 2010). A subsequent study confirmed the $I_{\mathrm{h}}$ loss and gating change and showed transcriptional downregulation of HCN1 mRNA expression, with onset by $3 \mathrm{~d}$ post-SE (Marcelin et al., 2009). Using the KA model, another study showed a similar loss of dendritic $I_{\mathrm{h}}$ in chronic epilepsy, although no loss of dendritic HCN channel expression had occurred by $1-2 \mathrm{~d}$ post-SE (Shin et al., 2008). Thus, multiple studies describe loss of HCN1 channel expression in chronic epilepsy, but differ somewhat in their characterization of its onset and the underlying mechanisms. To better understand acquired HCN1 channelopathy in epilepsy, we sought to determine its onset after pilocarpine-induced SE and test the involvement of both transcriptional and nontranscriptional mechanisms.

\section{Materials and Methods}

Electrophysiology. Hippocampal slices $(400 \mu \mathrm{m})$ were prepared from 6to 10 -week-old male Sprague Dawley rats (Jung et al., 2007). $I_{\mathrm{h}}$ amplitudes from dendritic cell-attached patch-clamp recordings at maximal voltage-dependent activation $(\sim-150 \mathrm{mV})$ are presented without correction for estimated patch area; however, pipette tip diameter $(\sim 1 \mu \mathrm{m})$ was held constant, and each investigator performed his own control series to minimize the effects of differences in pipette fabrication. All supplies were purchased from Sigma-Aldrich unless otherwise noted.

Pilocarpine model. We administered pilocarpine hydrochloride (385 $\mathrm{mg} / \mathrm{kg}$ i.p.) to induce SE in male Sprague Dawley rats 6-8 weeks of age (Jung et al., 2007). After $1 \mathrm{~h}$ in SE in animals studied at $1 \mathrm{~d}$ post-SE or longer, seizures were terminated with diazepam ( $12 \mathrm{mg} / \mathrm{kg}$, i.p.; Hospira) delivered every $30 \mathrm{~min}$ as needed. Animals studied at $1 \mathrm{~h}$ post-SE were sacrificed with ketamine/xylazine terminal anesthesia without administration of diazepam, and brain slices were used after $1 \mathrm{~h}$ incubation at room temperature. 
In vitro $S E$ model. Hippocampal slices from naive animals were perfused at $30-32^{\circ} \mathrm{C}$ with extracellular recording solution (Jung et al., 2007) containing $0 \mathrm{Mg}^{2+}$ and $50 \mu \mathrm{M}$ bicuculline and stimulated extracellularly using bipolar sharpened tungsten electrodes (A-M Systems) placed in the CA1 stratum lacunosummoleculare with five constant current $100 \mu \mathrm{s}$ pulses at $50 \mathrm{~Hz}$, delivered every $2 \mathrm{~min}$ for $1 \mathrm{~h}$. During perfusion, extracellular recordings were performed in stratum pyramidale with patch pipettes filled with $2 \mathrm{M} \mathrm{NaCl}$ solution. Following the perfusion, the bath was switched to normal solution and dendritic $I_{\mathrm{h}}$ recordings were made within an hour.

Western blotting. HCN1 channel protein levels were measured using a modified protocol (Jung et al., 2007). In each experiment, we pooled 6-8 hippocampal slices from a single animal prepared in the same way as for electrophysiology. The CA1 regions were microdissected on dry ice and homogenized in solution containing the following (in $\mathrm{mm}$ ): 4 paranitrophenylphosphate, 1 sodium orthovanadate, 1 phenylmethylsulfonyl fluoride, and protease inhibitor mixture ( 1 tablet per $10 \mathrm{ml}$; Roche). Homogenates were centrifuged at $15,000 \times g$ for $40 \mathrm{~min}$ at $4^{\circ} \mathrm{C}$. The pellet was then resuspended with sonication in homogenization solution and then run in Laëmmli buffer (with final concentration of $4.5 \%$ SDS) on a $10 \%$ acrylamide gel, transferred to a nitrocellulose membrane, and incubated with HCN1 antibody (1:500; Neuromabs), followed by incubation in antimouse secondary antibody (1:1000; Invitrogen) and visualized by enhanced chemiluminescence and film exposure. Three different protein loading amounts were used in each condition so as to verify that signal detection was in the linear range, as described previously (Jung et al., 2010). The membrane was then reprobed using anti- $\beta$-tubulin III antibody as a marker for neuronal protein content (1:20,000; SigmaAldrich), followed by incubation in anti-mouse secondary antibody (1: 20,000; Sigma-Aldrich). All reported HCN1 protein levels were normalized to $\beta$-tubulin III protein levels.

Surface biotinylation assay. Surface membrane protein expression was measured using a biotinylation protocol (Lugo et al., 2008). We prepared hippocampal slices and incubated them for $45 \mathrm{~min}$ on ice in extracellular recording solution containing $1.5 \mathrm{mg} / \mathrm{ml}$ sulfo-NHS-SS-biotin (Pierce) and then in extracellular solution with $1 \mu \mathrm{M}$ lysine to block all reactive sulfo-NHS-SS-biotin in excess. The CA1 regions were microdissected on dry ice and homogenized in buffer containing following (in $\mathrm{mm}$ ): $1 \%$ Triton X-100, 50 Tris- $\mathrm{HCl}, \mathrm{pH}$ 7.5, $150 \mathrm{NaCl}, 1$ EDTA, 1 sodium orthovanadate, and protease inhibitor mixture. The homogenates were centrifuged at $15,000 \times g$ for $15 \mathrm{~min}$ at $4^{\circ} \mathrm{C}$, and the supernatant was harvested. After the measurement of protein concentration with a BCA protocol $(\sim 800 \mu \mathrm{g}$ in $400 \mu \mathrm{l})$ and normalization of the inputs for total protein content, the supernatant was incubated with NeutrAvidin Plus beads (Pierce) overnight at $4^{\circ} \mathrm{C}$ and then washed three times with homogenization buffer. After centrifugation at $13,000 \times g$ for $5 \mathrm{~min}$, the supernatant was discarded and the beads resuspended in Laëmmli buffer (with final concentration of $6 \%$ SDS), and boiled. Total protein $(\sim 60 \mu \mathrm{g}$ in total loaded for gel electrophoresis) and biotinylated surface protein ( $50 \%$ of recovered surface protein in total loaded for gel electrophoresis) levels were analyzed using Western blotting. To confirm the absence of cytoplasmic proteins in the surface fraction, all blots were reprobed using anti-actin antibody (1:10,000; Sigma-Aldrich) followed by incubation in anti-rabbit secondary antibody (1:20,000; Invitrogen).

Real-time reverse transcription-PCR. HCN1 mRNA levels in CA1 hippocampus were determined using relative quantification with $\beta$-actin as the reference gene and forward/reverse primers and hybridization probes as described previously (Chen et al., 2005; Marce- lin et al., 2009). Data at each experimental time point post-SE were compared to its own control series. Reaction conditions were $3.125 \mu \mathrm{l}$ of Maxima Probe/ROX qPCR Master Mix (Fermentas) with cDNA dissolved in $1.25 \mu \mathrm{l}$ of diethylpyrocarbonate- $\mathrm{H}_{2} \mathrm{O}$ brought to $6.25 \mu \mathrm{l}$ with nuclease-free water. Reactions were analyzed in triplets. After preincubation for $2 \mathrm{~min}$ at $50^{\circ} \mathrm{C}$ and $10 \mathrm{~min}$ at $94^{\circ} \mathrm{C}, 40$ cycles of the PCR were performed ( $15 \mathrm{~s}$ at $94^{\circ} \mathrm{C}$ followed by $1 \mathrm{~min}$ at $59^{\circ} \mathrm{C} ; 7900 \mathrm{HT}$, Applied Biosystems).

\section{Results}

\section{Rapid loss of dendritic $I_{\mathrm{h}}$ post-SE}

To examine the time course of HCN1 channel loss post-SE, we performed cell-attached patch-clamp recordings in the apical dendrites of CA1 hippocampal pyramidal neurons (at $\sim 200 \mu \mathrm{m}$ from the soma) in brain slices of pilocarpine-treated and control animals. Maximal $I_{\mathrm{h}}$ amplitudes were significantly reduced at $1 \mathrm{~h}$ post-SE (control, $43 \pm 5.9 \mathrm{pA}, n=10 ; 1 \mathrm{~h}, 23.3 \pm 3.4 \mathrm{pA}, n=10$; $53 \pm 7.9 \%$ of control; $p<0.05$ by ANOVA). $I_{\mathrm{h}}$ remained decreased $1 \mathrm{~d}$ post-SE $(12.6 \pm 1.9 \mathrm{pA}, n=5 ; 30 \pm 4.4 \%$ of control; $p<0.01$ by ANOVA). This decline in dendritic $I_{\mathrm{h}}$ was similar to that previously seen at 1 week post-SE (Jung et al., 2007), when animals are beginning to experience spontaneous seizures (18 \pm $3.9 \mathrm{pA}, n=10$; compared to a previous control series, $48 \pm 4.5$ $\mathrm{pA}, n=19 ; 38 \pm 8.1 \%$ of control, $p<0.01)$, and at 1 month post-SE (Jung et al., 2010), when virtually all animals are chronically epileptic ( $20 \pm 4.7 \mathrm{pA}, n=8$; compared to its control, $40 \pm$ $6.5 \mathrm{pA}, n=22 ; 50 \pm 11 \%$ of control, $p<0.05)$. Figure $1 A$ shows all $I_{\mathrm{h}}$ values post-SE as a percentage of control to facilitate comparison among experiments. This demonstrates that the persistent loss of $I_{\mathrm{h}}$ that occurs in the early and chronic phases of epilepsy begins as soon as $1 \mathrm{~h}$ post-SE, well before the onset of spontaneous seizures. $I_{\mathrm{h}}$ voltage-dependent activation at early time points post-SE was similar to that of control (half-activation voltage, $V_{1 / 2}$ in control: $-90 \pm 1.7 \mathrm{mV}, n=10 ; 1 \mathrm{~h}:-87 \pm 1.8$ $\mathrm{mV}, n=10 ; 1 \mathrm{~d}:-91 \pm 5.9 \mathrm{mV}, n=5, p>0.05$ by ANOVA; Fig. $1 \mathrm{~B})$. This is consistent with earlier results demonstrating that the hyperpolarized shift in $\mathrm{HCN}$ channel activation that occurs in 


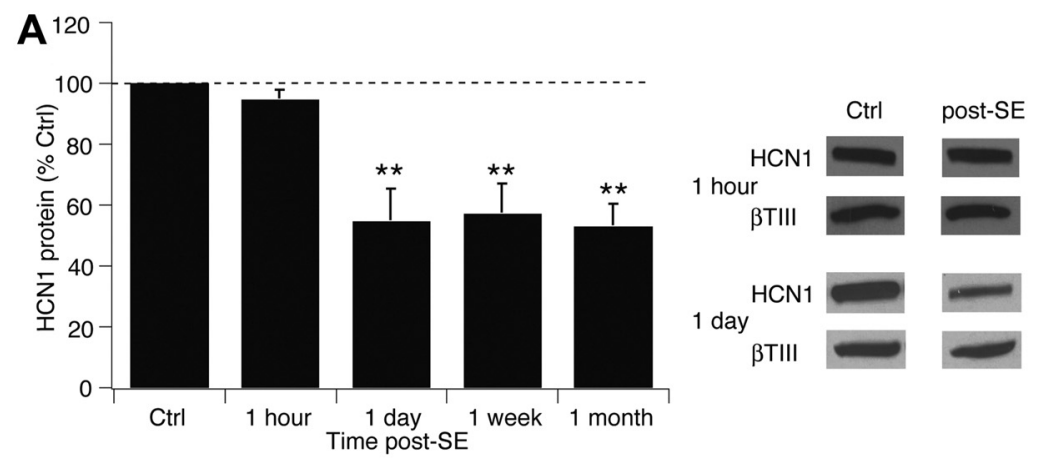

B
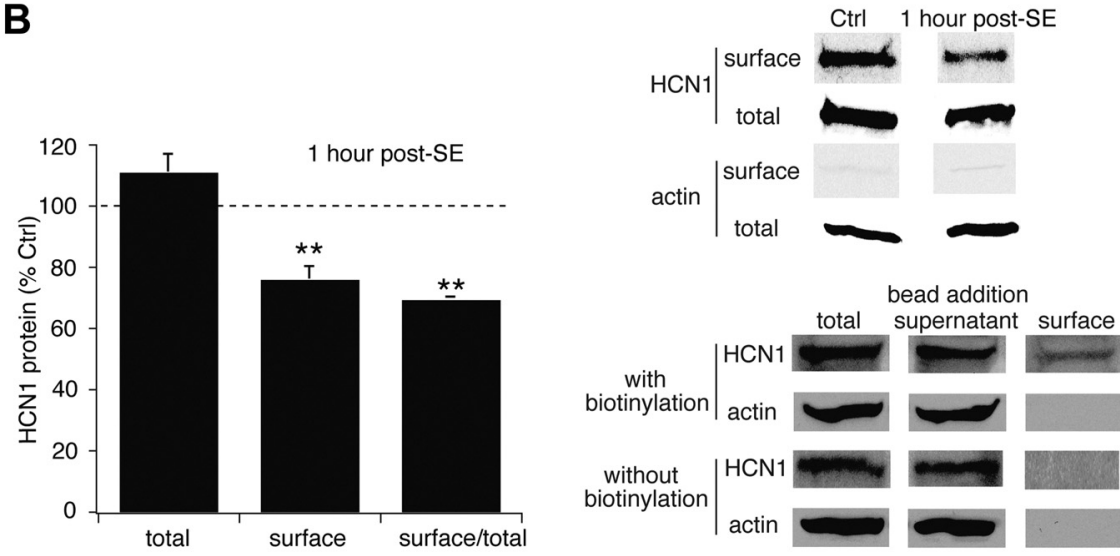

Figure 2. HCN1 channel protein expression falls after a delay following SE, while surface expression declines immediately at $1 \mathrm{~h}$ post-SE. $\boldsymbol{A}, \mathrm{HCN} 1$ channel protein expression at $1 \mathrm{~h}$ post-SE was unchanged, while at $1 \mathrm{~d}$ post-SE was decreased and remained reduced for at least 1 month. Representative blots are shown in each condition, along with blots of $\beta$-tubulin III as a marker of neuronal protein content. Summary data at 1 week and 1 month are from Jung et al., (2007). B, Expression of surface HCN1 channel protein was decreased at $1 \mathrm{~h}$ post-SE compared to control (Ctrl). Control and post-SE samples were processed in the same gel to enable accurate comparison; total and surface samples were processed in separate gels and thus cannot be directly compared. Lack of actin staining in the surface fraction confirmed the absence of cytoplasmic proteins. Bottom panels from a single representative gel show that no surface protein was recovered with avidin-complexed beads when biotinylation was omitted.

epilepsy and is mediated by loss of phosphorylation signaling depends on the occurrence of spontaneous seizures (Jung et al., 2007, 2010).

\section{Delayed loss of HCN1 channel protein expression post-SE}

HCN1 channel protein expression measured with Western blotting in CA1 hippocampus at $1 \mathrm{~h}$ post-SE was unchanged (95 \pm $2.9 \%$ of control, $n=5, p>0.05$; Fig. $2 A$ ) but was significantly reduced at $1 \mathrm{~d}$ post-SE $(54 \pm 10 \%, n=11, p<0.01)$. Although we normalized HCN1 channel protein values to those of $\beta$-tubulin III expression to control for any changes in neuronal protein content, at $1 \mathrm{~d}$ post-SE there was no significant change in $\beta$-tubulin III expression compared to that in control (101 \pm $7.0 \%, n=11, p>0.05$ ), suggesting a lack of neuronal death at that time point. The loss of HCN1 protein expression was similar to that previously seen at 1 week $(57 \pm 9.6 \%, n=6)$ and 1 month post-SE ( $53 \pm 7.1 \%, n=5$; Jung et al., 2007) and of similar magnitude to the loss of $I_{\mathrm{h}}$. Thus, decreased $I_{\mathrm{h}}$ amplitude at $1 \mathrm{~d}$ post-SE and beyond likely reflected a loss of HCN1 channel subunits. We did not examine HCN2 channel expression, as these subunits represent only a minority of $\mathrm{HCN}$ channel expression in hippocampus (Santoro et al., 2000) and are only transiently downregulated post-SE (Jung et al., 2007).

\section{Rapid internalization of $\mathrm{HCN1}$ channels post-SE}

Because $I_{\mathrm{h}}$ amplitude was reduced at $1 \mathrm{~h}$ post-SE while HCN1 protein expression remained intact, we hypothesized that $\mathrm{HCN} 1$ channel subunits had become nonfunctional by internalization from the surface membrane. Surface expression of HCN1 subunits measured with a biotinylation protocol was significantly reduced at $1 \mathrm{~h}$ post-SE $(76 \pm 4.0 \%$ of control, $n=5, p<$ 0.01 ; Fig. $2 B$ ), while total expression of the HCN1 subunit was not significantly altered $(111 \pm 6.0 \%, n=5, p>0.05)$. Surface normalized to total HCN1 levels were further decreased $(69 \pm 1.0 \%, n=5, p<$ $0.01)$. These results suggest that SE rapidly induces internalization of dendritic HCN1 channels, which undergo subsequent degradation by $1 \mathrm{~d}$ post-SE.

\section{Late transcriptional downregulation of HCN1 mRNA post-SE}

HCN1 mRNA expression diminishes as soon as $3 \mathrm{~d}$ post-SE, reflecting reduced transcription of the HCN1 gene (Marcelin et al., 2009). We performed real-time quantitative RT-PCR and found that HCN1 mRNA expression in the CA1 hippocampus at $1 \mathrm{~h}$ and $1 \mathrm{~d}$ post-SE was unchanged compared to control $(1 \mathrm{~h}, 124 \pm 9.1 \%, n=6 ; 1 \mathrm{~d}, 90 \pm$ $14.4 \%, n=6, p>0.05$ by ANOVA; Fig. 3 ), showing that the loss of $I_{\mathrm{h}}$ and HCN1 protein expression within the first day post-SE was not due to transcriptional downregulation of HCN1 mRNA expression. However, HCN1 mRNA levels at 1 week post-SE were significantly decreased compared to control levels (45 $\pm 7.0 \%$, $n=6, p<0.01)$. HCN1 mRNA levels at 1 month post-SE were not significantly decreased compared to control (74 $\pm 8.2 \%, n=10, p=0.08)$. These results show that transcriptional downregulation of HCN1 mRNA after SE follows early nontranscriptional processes of channel internalization and loss of protein expression.

An in vitro model replicates rapid loss of dendritic $I_{\mathrm{h}}$ post-SE We then asked whether the rapid loss of $I_{\mathrm{h}}$ post-SE could be reproduced in an in vitro model using naive tissue. Previously, an in vitro model of seizures provoked by extracellular bath perfusate containing $0 \mathrm{Mg}^{2+}$ and $50 \mu \mathrm{M}$ bicuculline maintained at 35$37^{\circ} \mathrm{C}$ yielded extracellularly recorded "seizure-like events (SLEs)" (Jung et al., 2010). During 1 h of these "in vitro seizure" conditions, an average of $\sim 3$ spontaneous SLEs occurred, associated with a hyperpolarizing shift in $I_{\mathrm{h}}$ activation but no significant change in maximal $I_{\mathrm{h}}$ amplitude. Since SE consists of nearly continuous seizure activity, we used similar conditions as in the in vitro seizure model, but evoked SLEs every 2 min with extracellular stimulation of perforant path afferents to area CA1. This "in vitro SE" protocol evoked 30 SLEs per hour manifested by extracellularly recorded outward current sources followed by slow inward current sinks on which were superimposed multiple rhythmic spike discharges (Fig. 4A). Whole-cell current-clamp recordings from CA1 pyramidal neuron somata during these evoked SLEs showed a prolonged depolarization of membrane potential associated with high-frequency action potential firing (Fig. 4A). 
We measured dendritic $I_{\mathrm{h}}$ after subjecting naive slices to $1 \mathrm{~h}$ of the in vitro SE protocol and then returning to normal recording solution. Similar to what was seen $1 \mathrm{~h}$ post-SE in vivo, dendritic $I_{\mathrm{h}}$ amplitude was significantly reduced compared to a new control series collected for this experiment (control, $63 \pm 7.1 \mathrm{pA}, n=9$; in vitro SE, $29 \pm 7.1 \mathrm{pA}, 45 \pm 11 \%$ of control, $n=6, p<0.01$; Fig. $4 B)$. Interestingly, $I_{\mathrm{h}}$ activation was hyperpolarized, as was seen with the in vitro seizure protocol ( $V_{1 / 2}$ in in vitro $\mathrm{SE},-105 \pm 2.1$ $\mathrm{mV}, n=6$; control, $-95 \pm 1.7 \mathrm{mV}, n=9, p<0.01)$. Because other studies had demonstrated transient changes in ion channel surface expression with exposure to glutamate (Kim et al., 2007; Noam et al., 2010), we examined whether glutamate receptor activation by itself would provoke loss of dendritic $I_{\mathrm{h}}$ amplitudes. During $1 \mathrm{~h}$ incubation of naive slices in normal recording solution with $100 \mu \mathrm{M}$ glutamate added, brief runs of interictal spikelike activity without spontaneous SLEs were observed with extracellular recording ( $n=6$ slices); during whole-cell current-clamp recording at the soma, occasional spontaneous EPSPs and action potentials were seen (Fig. 4A). Resting potential during glutamate application $(-64 \pm 0.91 \mathrm{mV}, n=4)$ was similar to control $(-62 \pm 3.8 \mathrm{mV}, n=9, p>$ $0.05)$. Incubation with glutamate did not significantly affect dendritic $I_{\mathrm{h}}$ amplitudes when measured after return to normal solution $(51 \pm 13 \mathrm{pA}, 81 \pm 21 \%$ of control, $n=8, p>0.05$ vs control; Fig. $4 B$ ). Thus, the early loss of $I_{\mathrm{h}}$ following SE in vivo can be replicated using an in vitro model of SE, demonstrating that this phenomenon depends on high levels of network activity and is not specific to pilocarpine-induced SE.

\section{Discussion}

\section{Rapid onset of HCN1 channelopathy}

We found that HCN1 channel loss begins within the first hour post-SE, is persistent, and occurs via three sequential mechanisms: a loss of HCN1 channel surface expression within the first hour; a loss of protein expression within the first day; and transcriptional downregulation that began within a week. Since we had previously shown that spontaneous seizures do not begin in our model until at least $3 \mathrm{~d}$ post-SE (Jung et al., 2007), the current study confirms that HCN1 channel loss clearly precedes spontaneous seizure onset. HCN1 channels thus join a limited set of voltage- and ligand-gated ion channels whose expression is dysregulated early in acquired epilepsy models and that cause hyperexcitability, including various $\mathrm{GABA}_{\mathrm{A}} \mathrm{R}$ subunits (Brooks-Kayal et al., 1998; Goodkin et al., 2008), Cav3.2 channels (Becker et al., 2008), Kv4.2 channels (Bernard et al., 2004; Lugo et al., 2008), and AMPARs (Rakhade et al., 2008). While multiple studies have consistently found loss of $I_{\mathrm{h}}$ and $\mathrm{HCN}$ channel expression in chronic phases of epilepsy post-SE, these same changes observed at early time points post-pilocarpine have been only variably observed early post-KA (Shah et al., 2004; Shin et al., 2008).

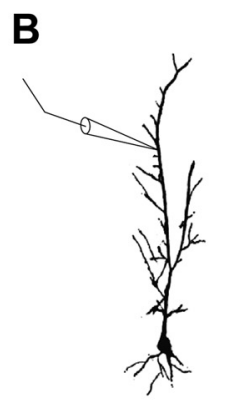
no significant effect. Ctrl, Control.

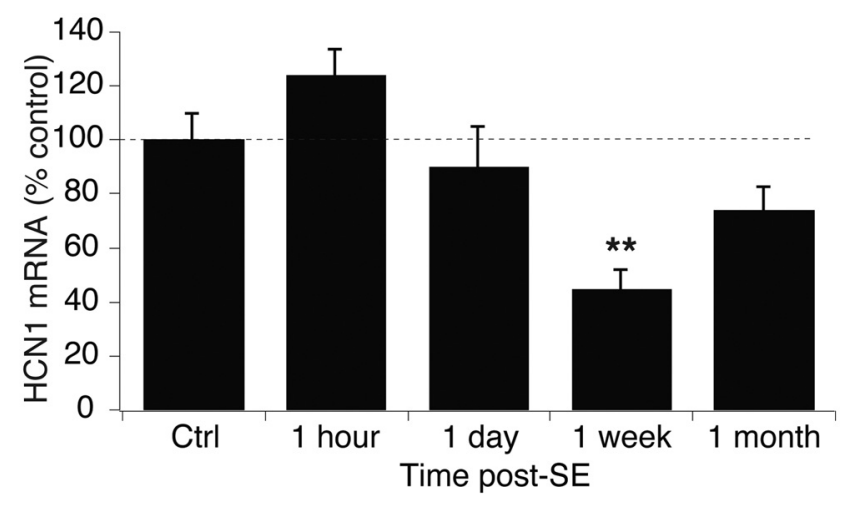

Figure 3. HCN1 mRNA levels are reduced within 1 week post-SE. HCN1 mRNA levels were unchanged at $1 \mathrm{~h}$ and $1 \mathrm{~d}$ post-SE, but were significantly reduced at 1 week post-SE. Control (Ctrl) data from the $1 \mathrm{~h}$ time point are shown.
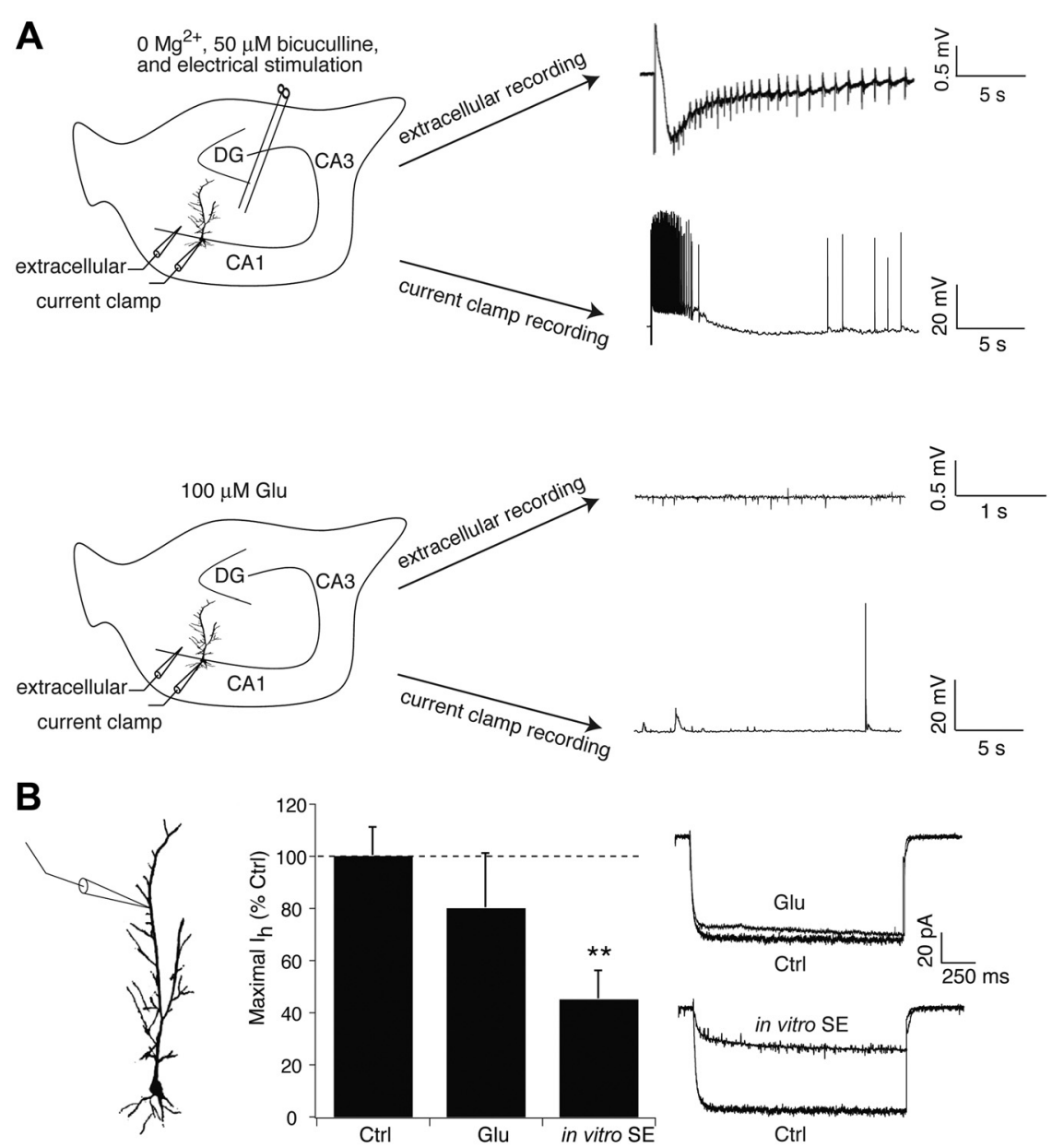

Figure 4. Dendritic $I_{\mathrm{h}}$ is reduced in an in vitro model of SE. $\boldsymbol{A}$, Representative traces show an evoked seizure-like event in both extracellular and whole-cell current-clamp recordings in the presence of bath solution with $0 \mathrm{Mg}^{2+}$ and $50 \mu \mathrm{m}$ bicuculline with extracellular stimulation of perforant path afferents. In the presence of $100 \mu \mathrm{m}$ glutamate alone, only modest spontaneous excitatory activity is seen. Example traces were not obtained simultaneously. DG, Dentate gyrus. $\boldsymbol{B}$, In vitro SE conditions for $1 \mathrm{~h}$ caused a significant decrease in dendritic $I_{\mathrm{h}}$ amplitude compared to control, while $100 \mu \mathrm{m}$ glutamate (Glu) application for $1 \mathrm{~h}$ had

These model-specific differences in the time course of HCN channelopathy may stem from the much slower development of epileptogenesis after KA compared to pilocarpine (Williams et al., 2007). 


\section{Nontranscriptional mechanisms underlie onset of HCN1 channelopathy}

Transcriptional downregulation of HCN1 mRNA expression had been widely assumed to underlie the loss of $\mathrm{HCN} 1$ channel expression in various epilepsy models (Richichi et al., 2008). However, the rapid onset of dendritic $I_{\mathrm{h}}$ loss following SE described here shows that this mechanism cannot be the sole explanation. Indeed, the first step in this process involves a reduction of the surface membrane expression of HCN1 channels, presumably mediated by a posttranslational modification of existing channels that alters their membrane stability. Similar processes mediated by altered phosphorylation of channel subunits have been demonstrated for the internalization of $\mathrm{GABA}_{\mathrm{A}}$ Rs post-SE (Terunuma et al., 2008) and Kv4.2 channels after SE or a glutamatergic stimulus (Kim et al., 2007; Lugo et al., 2008). Following rapid, putatively post-translational mechanisms, it appears that transcriptional downregulation occurs at a delay of at least several days from the initial loss of dendritic $\mathrm{HCN} 1$ expression. Determining whether transcriptional downregulation is dependent on or parallel to earlier regulatory processes will be important to understanding the cascade of events that leads to chronic loss of $\mathrm{HCN} 1$ channel expression. At a minimum, it appears that HCN1 channel dysregulation in epilepsy involves a combination of both post-translational and transcriptional mechanisms, much as occurs with $\mathrm{GABA}_{\mathrm{A}}$ Rs.

\section{Role of HCN1 channels in epileptogenesis}

Dendritic HCN1 channelopathy represents a single ion channel entity that is persistently dysregulated throughout epileptogenesis and chronic epilepsy, as has been corroborated by the time course of spontaneous seizures after pilocarpine-induced SE (Jung et al., 2007; Marcelin et al., 2009). Loss of HCN1 channel expression has also been shown in other animal models of acquired epilepsy, including KA-induced SE, perinatal hypoxia-ischemia (Zhang et al., 2006), and developmental cortical malformation models (Hablitz and Yang, 2010); but see (Chen et al., 2001). Recent reports have confirmed that HCN1 channel loss contributes to epileptogenesis, with deletion of the $H C N 1$ gene markedly accelerating the rate of epileptogenesis after provoked SE, even though HCN1 deletion does not by itself cause epilepsy (Huang et al., 2009; Santoro et al., 2010). HCN channel activity is upregulated by several antiepileptic drugs, possibly contributing to their mechanism of action (Poolos et al., 2002; Surges et al., 2003); thus, HCN1 channels may exert an antiepileptic as well as anti-epileptogenic action. Because HCN1 channel downregulation occurs so rapidly after SE, study of its mechanisms may provide insight into some of the earliest processes underlying epileptogenesis. The in vitro SE model characterized here may allow easier study of the mechanisms underlying the rapid loss of $I_{\mathrm{h}}$ and internalization of HCN1 channel subunits that occurs in the first hour post-SE.

\section{References}

Becker AJ, Pitsch J, Sochivko D, Opitz T, Staniek M, Chen CC, Campbell KP, Schoch S, Yaari Y, Beck H (2008) Transcriptional upregulation of Cav3.2 mediates epileptogenesis in the pilocarpine model of epilepsy. J Neurosci 28:13341-13353.

Bernard C, Anderson A, Becker A, Poolos NP, Beck H, Johnston D (2004) Acquired dendritic channelopathy in temporal lobe epilepsy. Science 305:532-535.

Brooks-Kayal AR, Shumate MD, Jin H, Rikhter TY, Coulter DA (1998) Selective changes in single cell $\mathrm{GABA}_{\mathrm{A}}$ receptor subunit expression and function in temporal lobe epilepsy. Nat Med 4:1166-1172.

Chen J, Larionov S, Pitsch J, Hoerold N, Ullmann C, Elger CE, Schramm J, Becker AJ (2005) Expression analysis of metabotropic glutamate receptors I and III in mouse strains with different susceptibility to experimental temporal lobe epilepsy. Neurosci Lett 375:192-197.
Chen K, Aradi I, Thon N, Eghbal-Ahmadi M, Baram TZ, Soltesz I (2001) Persistently modified h-channels after complex febrile seizures convert the seizure-induced enhancement of inhibition to hyperexcitability. Nat Med 7:331-337.

Goodkin HP, Joshi S, Mtchedlishvili Z, Brar J, Kapur J (2008) Subunitspecific trafficking of $\mathrm{GABA}_{\mathrm{A}}$ receptors during status epilepticus. J Neurosci 28:2527-2538.

Hablitz JJ, Yang J (2010) Abnormal pyramidal cell morphology and HCN channel expression in cortical dysplasia. Epilepsia 51 [Suppl 3]:52-55.

Huang Z, Walker MC, Shah MM (2009) Loss of dendritic HCN1 subunits enhances cortical excitability and epileptogenesis. J Neurosci 29:10979-10988.

Jung S, Jones TD, Lugo JN Jr, Sheerin AH, Miller JW, D’Ambrosio R, Anderson AE, Poolos NP (2007) Progressive dendritic HCN channelopathy during epileptogenesis in the rat pilocarpine model of epilepsy. J Neurosci 27:13012-13021.

Jung S, Bullis JB, Lau IH, Jones TD, Warner LN, Poolos NP (2010) Downregulation of dendritic $\mathrm{HCN}$ channel gating in epilepsy is mediated by altered phosphorylation signalling. J Neurosci 30:6678-6688.

Kim J, Jung SC, Clemens AM, Petralia RS, Hoffman DA (2007) Regulation of dendritic excitability by activity-dependent trafficking of the A-type $\mathrm{K}^{+}$channel subunit Kv4.2 in hippocampal neurons. Neuron 54:933-947.

Lewis AS, Chetkovich DM (2011) HCN channels in behavior and neurological disease: too hyper or not active enough? Mol Cell Neurosci 46:357-367.

Lugo JN, Barnwell LF, Ren Y, Lee WL, Johnston LD, Kim R, Hrachovy RA, Sweatt JD, Anderson AE (2008) Altered phosphorylation and localization of the A-type channel, Kv4.2 in status epilepticus. J Neurochem 106:1929-1940.

Marcelin B, Chauvière L, Becker A, Migliore M, Esclapez M, Bernard C (2009) h channel-dependent deficit of theta oscillation resonance and phase shift in temporal lobe epilepsy. Neurobiol Dis 33:436-447.

Noam Y, Zha Q, Phan L, Wu RL, Chetkovich DM, Wadman WJ, Baram TZ (2010) Trafficking and surface expression of hyperpolarization-activated cyclic nucleotide-gated channels in hippocampal neurons. J Biol Chem 285:14724-14736.

Poolos NP, Migliore M, Johnston D (2002) Pharmacological upregulation of h-channels reduces the excitability of pyramidal neuron dendrites. Nat Neurosci 5:767-774.

Rakhade SN, Zhou C, Aujla PK, Fishman R, Sucher NJ, Jensen FE (2008) Early alterations of AMPA receptors mediate synaptic potentiation induced by neonatal seizures. J Neurosci 28:7979-7990.

Richichi C, Brewster AL, Bender RA, Simeone TA, Zha Q, Yin HZ, Weiss JH, Baram TZ (2008) Mechanisms of seizure-induced 'transcriptional channelopathy' of hyperpolarization-activated cyclic nucleotide gated (HCN) channels. Neurobiol Dis 29:297-305

Santoro B, Chen S, Luthi A, Pavlidis P, Shumyatsky GP, Tibbs GR, Siegelbaum SA (2000) Molecular and functional heterogeneity of hyperpolarization-activated pacemaker channels in the mouse CNS. J Neurosci 20:5264-5275.

Santoro B, Lee JY, Englot DJ, Gildersleeve S, Piskorowski RA, Siegelbaum SA, Winawer MR, Blumenfeld H (2010) Increased seizure severity and seizurerelated death in mice lacking HCN1 channels. Epilepsia 51:1624-1627.

Shah MM, Anderson AE, Leung V, Lin X, Johnston D (2004) Seizureinduced plasticity of h channels in entorhinal cortical layer III pyramidal neurons. Neuron 44:495-508.

Shin M, Brager D, Jaramillo TC, Johnston D, Chetkovich DM (2008) Mislocalization of $\mathrm{h}$ channel subunits underlies h channelopathy in temporal lobe epilepsy. Neurobiol Dis 32:26-36.

Surges R, Freiman TM, Feuerstein TJ (2003) Gabapentin increases the hyperpolarization-activated cation current $\mathrm{I}_{\mathrm{h}}$ in rat CA1 pyramidal cells. Epilepsia 44:150-156.

Terunuma M, Xu J, Vithlani M, Sieghart W, Kittler J, Pangalos M, Haydon PG, Coulter DA, Moss SJ (2008) Deficits in phosphorylation of $\mathrm{GABA}_{\mathrm{A}}$ receptors by intimately associated protein kinase $\mathrm{C}$ activity underlie compromised synaptic inhibition during status epilepticus. J Neurosci 28:376-384.

Williams PA, Hellier JL, White AM, Staley KJ, Dudek FE (2007) Development of spontaneous seizures after experimental status epilepticus: implications for understanding epileptogenesis. Epilepsia 48 [Suppl 5]: 157-163.

Zhang K, Peng BW, Sanchez RM (2006) Decreased $I_{\mathrm{H}}$ in hippocampal area CA1 pyramidal neurons after perinatal seizure-inducing hypoxia. Epilepsia 47:1023-1028. 